\title{
Erratum to: Vertebral abnormality without spine-curvature deformity on prenatal ultrasonography: sonographic findings and postnatal radiographic correlations
}

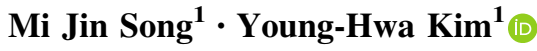

Published online: 7 August 2017

(C) The Japan Society of Ultrasonics in Medicine 2017

\section{Erratum to: J Med Ultrasonics \\ DOI 10.1007/s10396-017-0790-9}

In the original publication of the paper, the following sentence appearing at the last paragraph of the "Discussion" has been published incorrectly.

Prenatally diagnosed VA without SCD was the isolated type in $75 \%$ of live births in this study, which is much lower than seen in previous reports on hemivertebrae.

The correct sentence should be.

Prenatally diagnosed VA without SCD was the isolated type in $75 \%$ of live births in this study, which is much higher than the rate in previous reports on hemivertebrae.

The online version of the original article can be found under doi:10.1007/s10396-017-0790-9.

Young-Hwa Kim

daumykim@hanmail.net

Department of Radiology, Cheil General Hospital and Women's Healthcare Center, Dankook University College of Medicine, 17, Seoae-ro-1-gil, Jung-gu, Seoul 100-380, South Korea 